\title{
Personalisation in practice: The proven effects of personalisation
}

Received: 28th September, 2001
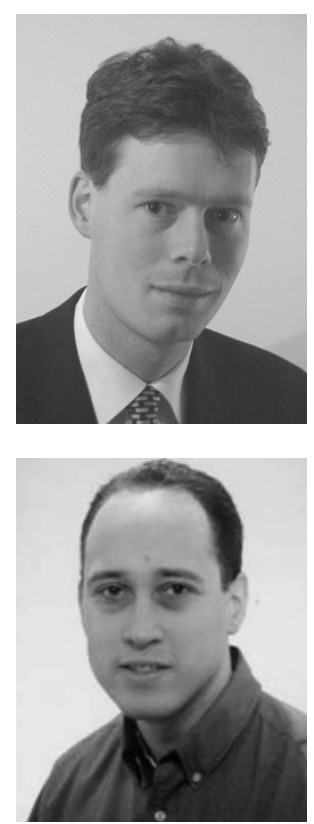

Oeds J. Postma Van Swietenstraat 41 2334EA Leiden, The Netherlands.

Tel: +31252 685265; e-mail: postmao@zonnet.nl

\section{Oeds J. Postma}

has been active in database marketing for several years. He has worked for Loyalty Management Netherlands (AirMiles) and VNU tijdschriften. Currently he advises several leading companies on how to apply database marketing principles to new media, such as e-mail, Web and SMS. In addition, he regularly speaks and publishes on pioneering database marketing issues.

\section{Marlon Brokke}

started as a database marketing analyst and is currently a senior CRM consultant at VNU, one of Europe's largest publishers. He advises the magazines' product managers on how to acquire, retain and develop their customers. He has participated in several customer loyalty projects. In the field of CRM he specialises in the use of online media such as direct e-mail to build customer relationships.

Abstract One of the key topics in direct marketing via the Internet is personalisation. In the past this way of communicating meant considerable extra costs. The Internet, however, has considerably lowered the incremental costs of personalising messages. E-mail has enabled companies to communicate with customers in a segmented way, without entailing extra physical costs. Personalisation is, therefore, becoming increasingly popular.

The underlying assumption behind these personalisation efforts is that 'sending the right message to the right customers will (dramatically) increase the effectiveness of communication'. This sounds logical, but little research has been done on the concrete effects of personalisation. This paper sheds more light on the issue, by demonstrating the effects of personalised communication as opposed to generic communication.

Although personalisation can be based on many things including behaviour, most companies start out with message differentiation based on preferences or characteristics as given by the customers. This paper examines the effects of this personalisation method in more detail.

\section{PERSONALISATION}

Although the general definitions tend to be similar, the term personalisation is used in several different ways. This is the definition that was used for this particular research: personalisation is a segmented form of communication that sends (groups of) different recipients different messages tailored to their individual preferences. Differentiation of content in this framework is more thorough than some classical interpretations of personalisation, which would consider a generic mail piece with a personal salutation as being personalised. For this research, respondents reported their items of interest, on the basis of which the messages were tailored.

This paper answers questions on personalisation in several ways. It starts by examining the effects that can be attributed to personalisation. It also provides a quantitative estimate of the effects. In addition to this, the research offers additional findings that are relevant for personalisation purposes. Although 
Table 1: Test design e-zine campaign

\begin{tabular}{llll}
\hline \multicolumn{4}{c}{ Test design } \\
\hline Group & 1 (test) & 2 (test) & 3 (control) \\
Offered personalised e-zine? & Yes & Yes & No \\
Responded? & Yes & No & Not applicable \\
E-zine version & Personalised & Standard & Standard \\
\hline
\end{tabular}

personalisation can be applied to many media like direct marketing, e-mail or websites, this research exclusively considers direct e-mail.

\section{RESEARCH BACKGROUND}

The research was conducted for a popular portal site, operated by a large publishing company. The portal attracts about 100,000 visits daily and collected a substantial number of opt-in e-mail addresses. In order to stimulate traffic to the site, to increase the number of repeat visits and to identify the characteristics and needs of the visitors, it was decided to experiment with a personalised e-mail newsletter (or e-zine). In order to identify the possible extra revenues associated with personalising the e-zine, a test campaign was created. The results of this exercise are summarised below.

\section{RESEARCH DESIGN}

The test campaign consisted of 11 weekly newsletters in two different versions: a standard non-personalised edition and a partly personalised one. Both e-zines were essentially identical in layout, and both versions always offered the same number of items. The content of the items was also identical apart from the last three items of the newsletter: in the personalised version these were based on the preferences indicated by the subscribers themselves. The non-personalised version contained standard choices picked by the editor.

The majority of the e-zine subscribers (who were until then only occasionally receiving plain newsletters) served as a test group and was thus given the option of receiving a personalised e-zine. In order to receive a personal version, these subscribers had to update their personal profile. This profile was gathered by a short webform that could be reached by clicking on the link in the invitation e-mail. The profile offered respondents the opportunity to choose their favourite items from a list of ten. In addition they had to rank their top three favourites. These three favourite items of interest were used for personalising the e-zines.

In order to gain full understanding of the effects of personalisation, a third group was selected to serve as a control. This group was not actively involved in the research and therefore received the standard newsletter, without ever having the opportunity to update their profile in order to receive a personalised version. The resulting test design is summarised in Table 1.

\section{RESEARCH RESULTS}

The goal of this particular research was to demonstrate the effects of personalising the e-zine. To achieve this, relevant measures were identified to serve as success indicators prior to the launch of the test campaign. Since the main goal was generating traffic to the website, it was agreed that success of the campaign would be measured through click-through behaviour of the subscribers. The following two specific measures were chosen:

- the total click-through rates (of 


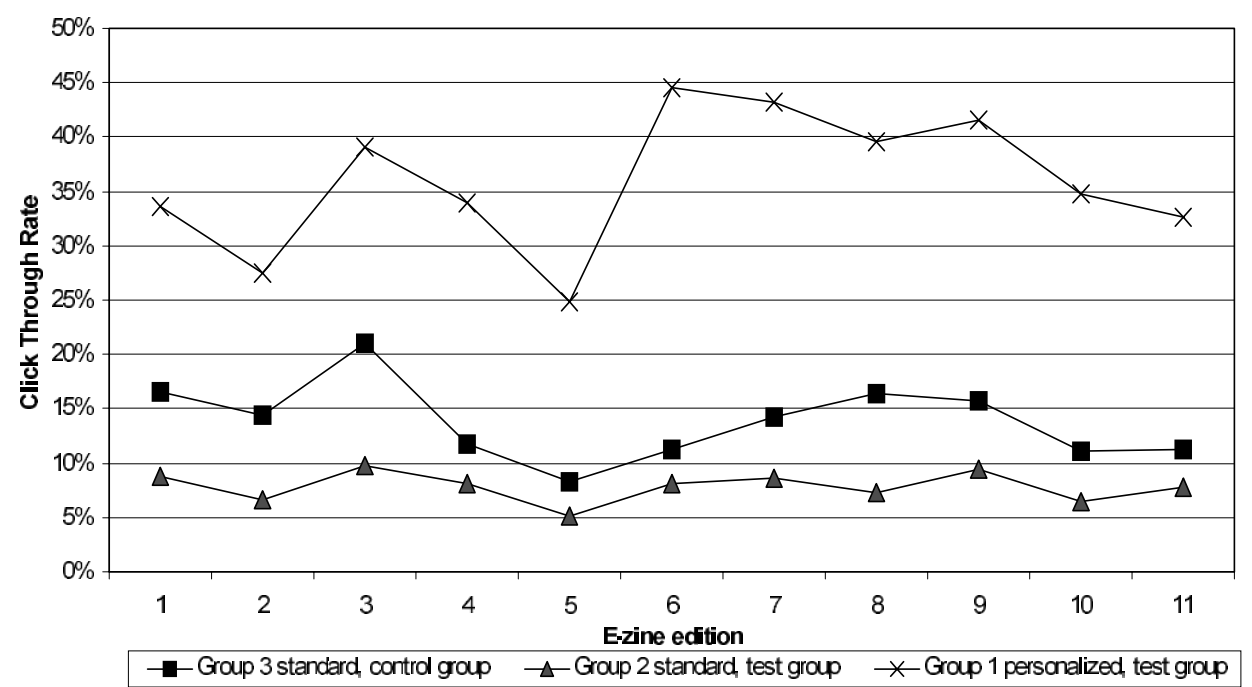

Figure 1 Click-through rates per e-zine version

recipients) that clicked on any of the links in the personalised e-zine as opposed to the competing generic e-zine

- the (personal) click-through rates of recipients on any of the personalised links as opposed to the competing generic links.

The remainder of this paper explores the differences in click-through rates (CTR) between the different e-zine versions. If personalisation works the CTR of the personalised versions would be expected to be higher than the standard version. Since the focus of the campaign was not on selling products, the data do not tell anything about buying behaviour or conversion rates. Similar results would, however, be expected in these events.

\section{Total click-through rates per e-zine version}

The most important result, from a marketing manager's point of view, is to understand the effects of personalisation on the number of click-throughs to the website. Figure 1 shows the total CTRs for the three e-zine versions per edition.

Figure 1 and Table 2 show the total click-through behaviour of the three groups. The most striking result is the much higher click through percentages for the personalised group (1) compared to the control group (3). On average, group 1 scores 2.6 times higher CTRs than the control group. This difference can be explained by two factors: the effects of personalisation and the effect of 'self-selection'. By self-selection is meant the distortion that arises because people had to participate to receive a personal version.

In this research, the test group was offered a personalised e-zine.

Consequently the more responsive people would be expected to be more willing to fill out the form and therefore reaching test group 1 . The resulting self-selection effect will bias the results, since it can be assumed that the more responsive people would exhibit higher CTRs because of their disposition. The opposite is also true; people who are less responsive are less likely to have filled out the web form in order to receive the personalised e-zine (group 2). This group therefore tends to show lower CTRs 
Table 2: Summary of click-through ratios per e-zine version

\begin{tabular}{llll}
\hline $\begin{array}{l}\text { Group } \\
\text { E-zine version }\end{array}$ & $\begin{array}{l}\text { Test group 1 } \\
\text { personalised }\end{array}$ & $\begin{array}{l}\text { Test group 2 } \\
\text { standard }\end{array}$ & $\begin{array}{l}\text { Control group 3 } \\
\text { standard }\end{array}$ \\
\hline $\begin{array}{l}\text { Average click-through rates } \\
\text { Index }\end{array}$ & $35.9 \%$ & $7.8 \%$ & $13.8 \%$ \\
\hline
\end{tabular}

Table 3: Summary of click-through rates per e-zine version

\begin{tabular}{lllll}
\hline $\begin{array}{l}\text { Group } \\
\begin{array}{l}\text { E-zine version } \\
\text { Responsiveness }\end{array}\end{array}$ & $\begin{array}{l}\text { Group 1 } \\
\text { personalised } \\
\text { responsive }\end{array}$ & $\begin{array}{l}\text { Group 2 } \\
\text { standard } \\
\text { not responsive }\end{array}$ & $\begin{array}{l}\text { Group 4 } \\
\text { standard } \\
\text { responsive }\end{array}$ & $\begin{array}{l}\text { Group 3 } \\
\text { (control) } \\
\text { standard } \\
\text { average }\end{array}$ \\
\hline $\begin{array}{l}\text { Average click-through rates } \\
\text { Index }\end{array}$ & $35.9 \%$ & $7.8 \%$ & $35.5 \%$ & $13.8 \%$ \\
\hline
\end{tabular}

automatically. This self-selection effect explains the lower click-through percentages of group 2 compared to group 1, where both groups received the standard version of the e-zine. On average, group 2 demonstrated a 43 per cent lower CTR than control group 3 . This result shows that the self-selection effect should not be underestimated.

Although this self-selection effect can be useful for database marketing purposes (like selecting the best scoring segments), it would not be right to attribute the higher CTRs of group 1 exclusively to personalisation of the e-zine. In order to eliminate this effect, a fourth (virtual) group was created. This group represents the more active and responsive people, had they received the standard version of the e-zine. The results of this group can be deducted from the data since the (weighed) average of CTRs of group 2 and this new group 4 has to be equal to the control group because they both received the standard e-zine. With the help of this fourth group, the self-selection effect was eliminated. In order to prove the unbiased personalisation effect, the click through behaviours of group 1 and group 4 were compared. The results are shown in Table 3.
The results of Table 3 show that a large part of the difference in CTRs between the personalised e-zine and the standard e-zine is explained by the self-selection effect; group 4 had a 4.5 times higher average CTR than group 2 . The effects of personalisation seemed very little; group 1 barely had a higher average CTR than group 4. This would mean that personalisation was not effective in generating more click-throughs to a website. A closer look at the data, however, revealed that the effect of personalisation increased in time. While in the first three editions the effect of personalisation on the CTRs was negative, it turned to a positive effect in the subsequent editions. Table 4 demonstrates the effect of personalisation over time by showing the average CTR of group 1 and 4 in three periods. Despite the very small overall effects, personalisation increased the CTRs by nearly 50 per cent in the last three editions.

When comparing the CTR of group 1 with that of group 4 , the higher CTR of group 1 was only caused by the last three items in the e-zine; all the other items (the majority by far) were identical in both versions. Therefore, the effects that could have been achieved by 


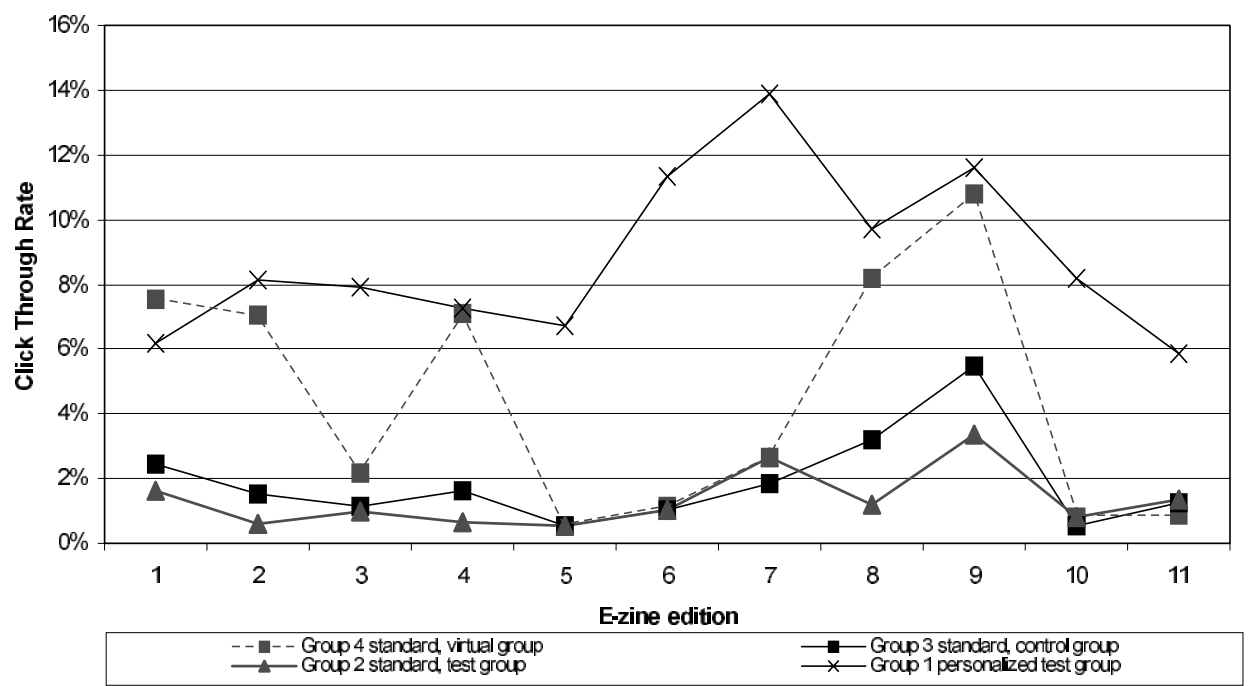

Figure 2 Click-through rates for personal items per version

Table 4: Effects of personalisation over time

\begin{tabular}{lllll}
\hline & \multicolumn{2}{l}{ Click-through rates } & Absolute difference & Relative difference \\
\cline { 2 - 5 } E-zine additions & $\begin{array}{l}\text { Group } \mathbf{1} \\
\%\end{array}$ & $\begin{array}{l}\text { Group } \\
\text { \% }\end{array}$ & $\%$ & $\%$ \\
\hline $1-4$ & 33.5 & 51.5 & -18 & -35 \\
$5-8$ & 38.0 & 28.0 & +10 & +36 \\
$9-11$ & 36.3 & 24.3 & +12 & +49 \\
\hline
\end{tabular}

Table 5: Summary of click-through rates for personal items per e-zine version

\begin{tabular}{|c|c|c|c|c|}
\hline $\begin{array}{l}\text { Group } \\
\text { E-zine version } \\
\text { Responsiveness }\end{array}$ & $\begin{array}{l}\text { Group } 1 \\
\text { personalised } \\
\text { responsive }\end{array}$ & $\begin{array}{l}\text { Group } 2 \\
\text { standard } \\
\text { not responsive }\end{array}$ & $\begin{array}{l}\text { Group } 4 \\
\text { standard } \\
\text { responsive } \\
\text { (reference) }\end{array}$ & $\begin{array}{l}\text { Group } 3 \\
\text { (control) } \\
\text { standard } \\
\text { average }\end{array}$ \\
\hline $\begin{array}{l}\text { Average click-through rates } \\
\text { Index }\end{array}$ & $\begin{array}{l}8.8 \% \\
469\end{array}$ & 72 & $\begin{array}{l}4.4 \% \\
236\end{array}$ & $100^{1.9 \%}$ \\
\hline
\end{tabular}

personalising all e-zine content are underestimated. The second part of this paper explores the full effects of personalisation, by considering these three personal items only.

\section{Click-through rates for the three personal items per e-zine version}

In order to estimate the full effects of personalising all the items in the e-zine, the CTRs for the three personal items were compared to the three editor-picked items. This way, the large number of identical items in both e-zine versions did not lessen the effects of personalisation. The results are shown in Figure 2 and Table 5.

The most obvious result is the much stronger effect of personalisation; the personal links (group 1) generated a 100 per cent higher average CTR than the 
Table 6: Influence of item preference on the click-through rates

\begin{tabular}{lccc}
\hline E-zine edition & Personal item 1 & Personal item 2 & Personal item 3 \\
\hline 1 & 2.21 & 2.21 & 1.77 \\
2 & 3.85 & 2.78 & 1.5 \\
3 & 2.36 & 3.86 & 1.72 \\
4 & 2.35 & 2.56 & 2.13 \\
5 & 3.17 & 1.87 & 1.49 \\
6 & 5.55 & 2.5 & 3.05 \\
7 & 5.81 & 3.61 & 4.27 \\
8 & 3.87 & 2.93 & 2.93 \\
9 & 3.97 & 3.65 & 3.55 \\
10 & 2.62 & 2.73 & 2.73 \\
11 & 1.57 & 2.2 & 1.78 \\
Average CTR & $3.4 \%$ & $2.8 \%$ & $2.5 \%$ \\
Index & 139 & 115 & 100 \\
\hline
\end{tabular}

editor-picked items for group 4

(8.8/4.4). The self-selection effect is also smaller; group 4 has a 3.2 times higher average CTR than group 2. This ratio was 4.5 when all items were involved in the calculations.

\section{ADDITIONAL FINDINGS}

One additional finding of this research that is worth mentioning in this paper is the effect of customer preference on the CTRs. When subscribing for the personalised e-zine, participants were specifically asked to rank their three favourite items of interest. An interesting question that arose during the research was to see if differences in behaviour could be found between the levels of preference. Table 5 shows the effects of this rank order on click behaviour.

The results show that the rank order is of influence. On average, items of first choice achieve better CTR than second choice items. Second best items score better than the third choice items. The average improvement for the second choice over the third choice is 15 per cent. The improvement of the first to the third is almost 40 per cent. This strongly suggests that the better the messages are tailored to recipients' preferences, the better the results will be. These results further support the conclusion that content targeting works and therefore that better-targeted personalisation triggers (more) response.

\section{CONCLUSIONS}

The research clearly shows that personalisation has profound effects; although a large part of the effect in this research was due to self-selection, the pure personalisation effect proved very strong as well. The average CTRs can be expected to double in the case of full personalisation. It also looks as if the personalisation effect grows over time. In the beginning people seem to click whether the e-zine is personalised or not. This is probably because recipients are curious. Later on this seems to change. Only the personalised items seem to continue to attract the interest of readers.

In addition, the self-selection effect has proved to be a good predictor of behaviour and can therefore be of help in direct marketing to optimise marketing campaigns.

The rank order results further support the notion that personalisation based on self-reported interests really works. The results also seem to suggest that even greater effects can be expected for even better personalised content. 